\title{
AC 2010-1091: RESTRUCTURING A DESIGN-FOCUSED INTRODUCTORY TRANSPORTATION ENGINEERING COURSE: AN EXPLORATORY STUDY USING THE THRESHOLD CONCEPT FRAMEWORK
}

\section{Dan Cernusca, Missouri University of Science and Technology}

Dr. Dan Cernusca is Instructional Design Specialist in the Department of Global Learning at the Missouri University of Science and Technology. He received his Ph.D. degree in Information Science and Learning Technologies in 2007 from University of Missouri - Columbia. He also holds a BS and a Ph.D. from the University of Sibiu, Romania with a specialization in manufacturing technologies and respectively cutting-tools design. His research interests include Design-Based Research in technology-enabled learning contexts, technology-mediated problem solving, assessment in technology rich learning environments, applications of dynamic modeling for learning of complex topics, and the impact of epistemic beliefs on learning with technology.

\section{Ghulam Bham, Missouri University of Science and Technology}

Dr. Ghulam Bham is an Assistant Professor of Civil Engineering at the Missouri University of Science \& Technology. He received his PhD from the University of Illinois at Urbana-Champaign in 2003. His research interests include modeling and simulation of driver behavior in transportation systems, traffic operations and control, and traffic safety. 


\title{
Restructuring a Design Focused Introductory Transportation Engineering Course: An Exploratory Study Using the Threshold Concept Framework
}

\begin{abstract}
Design is an integral part of engineering courses. Addressing design problems is a challenging task in instruction because of the openness and complexity of these problems. This paper presents an approach in addressing these challenges for an introductory transportationengineering course, an important part of which is highway design. To address the challenges associated with highway design, a framework proposed by the threshold concepts model was used to identify a candidate-concept for the instructional redesign process. Two major characteristics of threshold concepts, integrativity and transformativity were used to identify horizontal alignment candidate-concept for the highway design process.
\end{abstract}

Using concept maps generated as guides through the integrativity of learning associated with the horizontal alignment, several adjustments to the structure of lecture materials and project tasks were made. In addition, reflective assessment items were administered after each redesigned instructional task and at the end of the course. Students' answers to these reflective assessments helped identifying trends associated with the transformativity of horizontal alignment in the context of highway design. The analysis of students' reflective assessment indicated that horizontal alignment has the potential to be transformative, and therefore, can be a candidateconcept for the activities associated with scaffolding of highway design process.

\section{Introduction}

Streamlining the instructional activities was and will be an ongoing struggle both for instructors, at the classroom level, and administrators, at the institutional level. As each field of knowledge grows, students struggle with their transition from novice to expert in their academic growth. Addressing these struggles is even more stringent for design activities that are typically part of the engineering curriculum. Addressing design problems is and it will be a challenging task in instruction because of the openness and complexity of these problems ${ }^{1}$.

When scaffolding design activities in their courses instructors typically face challenges in balancing the content, as proposed by various textbooks they use, and the reality of their classroom instruction. That is, quite often instructors find that they have to develop additional instructional steps to address the gap between the existent and the expected levels of prior knowledge and skills their students need to successfully engage in the design activities. The instructor also needs to find ways to include these additional steps within the limited time allocated for that instructional process.

Attempts to address these challenges include the development and implementation of technology-based modules. In transportation engineering, for example, such technology-based modules provided, on one hand, more expertise-based activities for students ${ }^{2}$ and, on the other hand, moved some of the delivery of the content outside the classroom ${ }^{3}$. 
However, very often the technology-driven solutions, as the ones previously mentioned, tend to focus on how the strengths of chosen technology can improve very specific instructional tasks. This focus on specific instructional tasks does not answer instructor's need to restructure the instructional process at the discipline and curriculum levels to include the additional step previously mentioned. A more recent systemic approach in educational research that can address these issues at both the curriculum and discipline level is the model of Threshold Concepts introduced by Meyer and Land ${ }^{4}$. It proposes to carefully analyze and validate the instructional content only for those concepts that are critical for the practice of a given field.

\section{Conceptual Framework}

To address the challenges associated with highway design, a framework proposed by the threshold concepts model ${ }^{4,5}$ was used to narrow down and focus the instructional restructuring process. That is, the goal of this conceptual framework was not in the theoretical realm of identifying and documenting threshold concepts associated with the design of highways. Rather, the goral was a developmental one focusing on using major characteristics of threshold concepts to identify a candidate-concept that could produce significant positive impact on the quality of the restructured instructional process.

\section{$\underline{\text { Threshold Concepts }}$}

In an effort to streamline the process of curricula development within various disciplines, Meyer and Land ${ }^{4}$ introduced the threshold concepts as conceptual gateways that open new ways of thinking. In defining the threshold concept, they focused on those learning outcomes that push students to think in new ways that are both transformative and irreversible ${ }^{5}$. Three major characteristics are critical in recognizing threshold concepts ${ }^{4,5,6}$, that is, threshold concepts are integrative (integrativity), transformative (transformativity), and irreversible (irreversibility).

Integrativity is a major characteristic of threshold concepts and is reflected by the ability of these concepts to expose some otherwise hidden interrelatedness of the phenomenon being described by that concept.

Transformativity of a threshold concept involves a shift in understanding at both the conceptual and ontological levels. Because we are what we know, new understanding involves adjusting existing conceptual models to accommodate the new information. Very often, creating a conceptual shift requires also an ontological shift to allow the learner to include the new entities associated with learned concept into own activities ${ }^{7}$.

Finally, Irreversibility refers to the fact that the knowledge and skills associated with the learning of a threshold concept once mastered are unlikely to be forgotten even if likely they will be refined in time.

The major strength of this model is that it helps instructors define at the conceptual level the critical characteristics of such concepts and find applications to various fields. Along with the initial field of application, business and economics ${ }^{4,5,8}$, a large variety of domains such as biology ${ }^{9,10}$, computer programming ${ }^{11}$, mathematics and statistics ${ }^{12,13}$, and electrical engineering ${ }^{14}$ are applying them. 
To identify a candidate-concept that will help develop the effective instructional strategies to scaffold learning of design skills associated with specific design activities (highway design in this case), we focused on two of the three major characteristics of threshold concepts that can be evaluated within the given time framework associated with the educational program: integrativity and transformativity ${ }^{6}$. The third one, irreversibility would require a long-term aka longitudinal analysis of knowledge and skills built through the scaffolding of a given threshold concept.

As no definitive and clear practical strategies to operationalize integrativity are available in the literature, we proposed to use concept maps developed by the subject matter expert to expose the complexity and interrelatedness of the phenomenon associated with various design concepts. Then we selected the concept with higher integrativity as candidate concept to help guiding the redesign of various instructional tasks in the focal design activity.

The potential transformativity of this concept was then analyzed using two data sources. First students' perception and attitude toward the skills and abilities associated with the target concept were analyzed. Second instructor's insights on the impact of implementing the new instructional strategies complemented students' inputs.

\section{Theoretical and Empirical Grounds of Conceptual Mapping}

The analysis of meaning and its relationship with knowledge representation caught the attention of the researchers in the cognitive science field after the concept of schemata was proposed by Bartlett $^{15}$ to explain human memory ${ }^{16,17,18}$. With the growth of research in the field of information processing and the development of new representational tools, the interest in cognitive science towards schema theory and its applications for learning increased. The main research lines in schema theory focused on: a) linking schemata to memory representation through structural networks ${ }^{16}$; b) defining methods and tools to map cognitive structures ${ }^{17}$; c) representing knowledge in the memory as recursive conceptual structures embedded in hierarchies $^{18}$; and d) proposing instructional applications of schema theory ${ }^{19}$.

For example, by integrating semantic structures with structural networks, Thagard ${ }^{19}$ proposed a structure of conceptual systems that "consists of concepts organized into kind-hierarchies and part-hierarchies and linked to each other by rules" (p.30). Building on this hierarchical approach of schema theory, researchers focused on the measurement of the state of conceptual understanding. From this perspective, the state of conceptual understanding can be viewed as: a) the level of structural knowledge ${ }^{20}$; b) the combination of the levels of both declarative and structural knowledge ${ }^{21}$; and c) the combination of the levels of both declarative and structural knowledge $^{20}(\mathrm{p} .4)$.

The application of structural knowledge covers several aspects of the learning process. First, the instructors and researchers can build various representational tools to elicit the structural knowledge from both expert and novices and can determine the knowledge gaps to be addressed $^{20}$. Second, the instructors can convey to novice students complex conceptual patterns developed by experts using instructional tasks that include explicit knowledge representation tools $^{20,22}$. 
When exploring a given knowledge structure using concept maps, an expert selects a representative group of concepts and represents them as nodes organized in clusters of lateral and hierarchical concepts networked through directional links. For a given concept map the number of nodes represents the breadth, the number of hierarchical levels represents the depth, and the average number of links to and from a given node the connectedness of that map ${ }^{20}$. In this study, we used these characteristics to identify those design concepts that have a high degree of integrativity (as described above in the threshold concept model).

\section{Instructional Context}

Highway design and traffic engineering are two most commonly offered courses at US universities. These courses are offered with various titles however, the main content is quite similar. Transportation engineers mainly design highways, airports, traffic signals, analyze and evaluate performance of roads and highways, manage traffic, etc. Highway design is an integral part of civil engineering (CE) curriculum. Highway design is also a very important part of course work for students interested in transportation engineering. It prepares students for the FE (Fundamental of Engineering) examination and is part of the PE (Professional Engineering) examination.

Highway design is divided into horizontal and vertical alignments. Textbooks divide horizontal alignment into design of a horizontal curve by selecting the value of superelevation, and side friction factor based on speed. The minimum radius of a horizontal curve is then determined based on these values. Once the radius is known, various elements of a horizontal curve are calculated. Additionally, stopping sight distance for a horizontal curve, and the staking of a curve in the field are explained in most textbooks ${ }^{23}$. Moreover, some textbooks cover compound curves, length of spirals and present details of determining superelevation profile and their used with horizontal curves. The major issue with this approach is that design aspects of a horizontal alignment are barely covered. The major challenges for any design engineer are associated first with locating the points of intersection of tangents along the horizontal alignment and second points of vertical intersection for the vertical alignment to balance the cut and fill. These decisions are critical part of any highway design.

Design of horizontal and vertical alignments are also taught in most transportation engineering and highway design courses. For design of any highway alignment, horizontal alignment is decided first and then vertical alignment is designed, contrary to how it is presented in some textbooks (most commonly used text books present vertical alignment first and then the horizontal alignment is explained). The remaining part of this paper details the steps taken towards restructuring the material for highway alignment design covered under the mandatory Transportation Engineering course offered to civil engineering undergraduate students at a major Midwest engineering school. This course laboratory covers highway design activities as part of a class project.

\section{Research Questions and Method}

The overall objective of this study was to explore to what degree the use of the framework proposed by the model of threshold concepts can help to improve the learning process in a design-focused Transportation Engineering course. 
The main exploratory questions were:

(E1) To what degree the integrativity of a design concept captured with expert-built concept maps will help refine instructional tasks needed to scaffold the learning process of that design concept?

(E2) Once the instructional changes resulting from the analysis of integrative concepts are implemented in the classroom, to what degree will they transform students' perception of the design process?

To answer the above two exploratory questions we used a case study, a qualitative research analysis $^{25}$ built around the highway design process associated with a mandatory Transportation Engineering course. The instructor and an instructional designer having an engineering background developed and implemented a design-focused research procedure for this study (Table 1).

Table 1. Research Procedure and Associated Outcomes

\begin{tabular}{|c|c|}
\hline Research Procedure & Outcomes \\
\hline \multicolumn{2}{|c|}{ Integrativity and its role in the restructuring of the instructional process } \\
\hline $\begin{array}{l}\text { Step } 1 . \text { The instructor describes the major steps in } \\
\text { the highway design process and their connection } \\
\text { with concepts associated with basic and prerequisite } \\
\text { knowledge. }\end{array}$ & $\begin{array}{l}\text { Concept maps showing networking nodes } \\
\text { (concepts) and links (relationships) associated } \\
\text { with major highway design steps. }\end{array}$ \\
\hline $\begin{array}{l}\text { Step 2. Based on the breadth (number of nodes) and } \\
\text { connectedness (complexity of links between } \\
\text { concepts) the instructor selects a candidate } \\
\text { integrative concept. }\end{array}$ & $\begin{array}{l}\text { Horizontal Alignment was selected as the } \\
\text { candidate integrative concept to be used to } \\
\text { restructure the instructional process } \\
\text { associated with highway design. }\end{array}$ \\
\hline $\begin{array}{l}\text { Step 3. The instructor describes and prioritizes the } \\
\text { major steps in the design of Horizontal Alignment. }\end{array}$ & $\begin{array}{l}\text { Concept maps summarizing expert's } \\
\text { understanding of the major steps in the design } \\
\text { of Horizontal Alignment. }\end{array}$ \\
\hline $\begin{array}{l}\text { Step 4. The resulted concepts maps are used to } \\
\text { revise the existent instructional tasks associated with } \\
\text { the design of Horizontal Alignment. }\end{array}$ & $\begin{array}{l}\text { New lecture and project tasks and materials } \\
\text { that reflect the complexity of the design of } \\
\text { Horizontal Alignment are developed and } \\
\text { integrated in the existent instructional } \\
\text { material. }\end{array}$ \\
\hline
\end{tabular}

\section{Transformativity reflected in students' perception of instructional process}

Step 5. The new instructional process for the design of the Horizontal Alignment is deployed and monitored through a series of reflective assessment assignments.
Themes reflecting students' perceptions of various instructional steps introduced in the Horizontal Alignment design process.

The remaining part of the paper will detail the structure and the outcomes of the two major research stages associated with the role of the integrativity and transformativity of Horizontal Alignment in the restructuring of the highway design process in an undergraduate Transportation Engineering course. 


\section{Results and Interpretation}

Integrativity and its role in the restructuring of the instructional process

\section{Horizontal Alignment: an Integrative Concept in Highway Design Process}

The highway alignment comprises of horizontal and vertical elements. First, the horizontal alignment is designed and then the vertical alignment is proposed. Both horizontal and vertical alignments are critical aspects of highway design. However, as a first step in the process of highway design, horizontal alignment not only is a web of interconnected major concepts but also strongly connected to a series of prior knowledge and skills that are critical for this process.

To support this conclusion, Figure 1 exemplifies the concept map developed based on the instructor's description of the major concepts and related prior knowledge related to the design of horizontal alignment. The upper left corner of the map and the bottom left part of the map represent the expected types of prior knowledge (e.g. basic math and surveying prerequisite) that students need to master to be successful in this stage of the instructional process. The middle part of this concept map exemplifies some major learning outcomes resulting from this stage of the design process (e.g. elements of the curve, stopping sight distance). The middle part also shows the relationships of these major concepts to the prior knowledge and subsequent hierarchies of concepts that are part of this stage in the design process (e.g. specific elements of the curve, elements of the stopping sight distance). This conceptual structure provides a first, macro-level image of the integrativity of the horizontal alignment as a major step in the highway design process. None of the subsequent concepts used in the highway design process (e.g. vertical alignment, crown sections) surpassed horizontal alignment in breadth and depth when similar maps were considered.

As shown in the literature ${ }^{20}$, very often concept maps as artifacts are less important than the thinking process they support when developing them. This observation holds true for the analysis of the integrativity of horizontal alignment as well. That is, the map shown in Figure 1 can hardly be used by itself in teaching of the highway design to undergraduate students due to its relative complexity, but it certainly helped the instructor visualize the complexity of the connections associated with the given design concept. Consequently, by building a concept map similar to the one in Figure 1, an instructor will be able to understand better the types of instructional scaffolds needed to help students master the breadth and depth of knowledge associated with the target design concept.

\section{Location of Points of Intersection (PI): Micro-level Integrativity of Horizontal Alignment}

Once horizontal alignment selected as an integrative concept for the design of the highway, the next step was to move the analysis of integrativity to the micro-level of horizontal alignment as a design process by developing similar concept maps with the one previously described. 




Figure 1. Integrativity of horizontal alignment: major concepts and related prior knowledge

The most common perspective students get when first exposed to this step in the design process is that of the design procedure. In Figure 2, these steps are marked with (a) and represented in the middle part of the concept map developed to describe the horizontal design process. This procedural representation is a direct result of the linearity of materials in textbooks and other printed resources. Even from an instructional perspective a procedural approach can help learners ease into the understanding of the how's of the design process. See for example the steps grouped under Figure 2 (b), are based mainly on computing equation-driven data and, therefore, more likely to be presented in the instructional process either in a procedural manner or as worked examples. However, the main weakness of the procedural representation is that it does not reveal the why's that reflect the complexity of the design process. Therefore, very often this procedural approach deceives novice learners by guiding them toward forming simplified conceptual models about the design process. 
To help learners avoid this trap, the expert (the instructor in this case) developed several concept maps that expand on various layers of increased depth in connectivity among various concepts associated with the design of horizontal alignment. The one exemplified in this paper is the location of point of intersections that represent a second layer in the depth of describing the integrativity of the horizontal alignment design process.

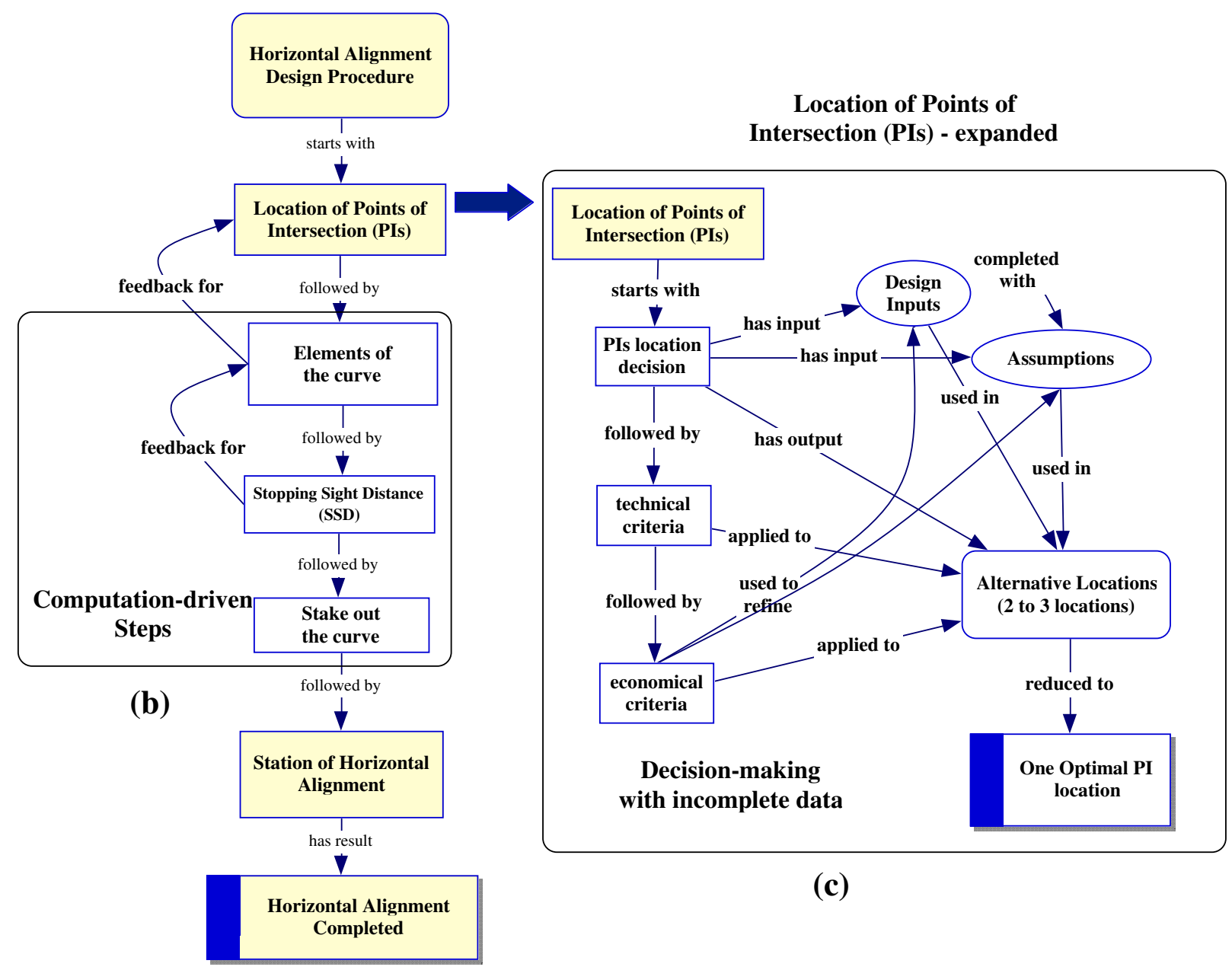

(a)

Figure 2. Integrativity of horizontal alignment: (a) design procedure; (b) steps that focus heavily on equation-driven data; (c) location of PIs expanded to reflect the complexity of this step

Designing horizontal curves requires as a major step, the location of points of intersection (PIs) for a horizontal curve to be decided. Instructor's experience showed that for students, especially for those not previously exposed to design tasks, the decision to determine the number of PIs and their locations is both important and challenging. This is even more challenging as students need to work with incomplete information provided by the design inputs, which requires them to make assumptions that need to be grounded in existing regulations and recommendations in the professional literature. 
If one adds to this, students have to accept that there can be more than one PI location solution then this concept has the potential to become either a significant barrier or a skills-leap opportunity when engaging in highway design. Additionally, there is no systematic method available to maximize design consistency in highway alignment $\operatorname{design}^{24}$.

Therefore, considering the skill-building role of horizontal alignment and the impact of the location of PIs as both a challenging and synergic concept, PI location will be used to exemplify elements associated with the integrativity of horizontal alignment as candidate concept to build instructional scaffolds to support building design skills for novice learners.

For example, Figure 2 presents under the group marked with (c) the major concepts associated with the location of PIs along with major interaction among them. It can be observed that the step marked in the central part as "Location of point of Intersections", is in fact a network that involves both technical and economical analyses. More important yet, this step requires as input not only design inputs easy to get from the technical description of the project but also assumptions. If making assumptions is typically based on experience for seasoned designers, for students building them requires searching in various sources of secondary data and regulations that the instructor needs to suggest and scaffold as part of the instructional process.

Finally, a last step in explicating the depth of integrativity of concepts associated with the horizontal alignment design process involves the development of concept maps for those concepts that represent iterations in the design process associated with the PIs location (e.g. PIs location, technical and economical analysis represented under section (c) in Figure 2 above).

Of these, Figure 3 exemplifies the technical analysis that results in the initial location of alternative PIs' locations. This map indicates both the types of design inputs students need to use and the design constraints they need to consider when balancing various design inputs in finding alternative locations for PIs. If for an expert this map is rather a simple decision making process, for undergraduate students used to solving problems that have clear results based on the application of a set of given equations, decision making is rather a cumbersome, hard to manage skill because of its "softness" and lack of clear success descriptors. It is, then, even more important to clearly describe these types of activities and make sure that needed instructional scaffolds are in place for students when they need them. Similar maps were developed for the technical and economical analysis of PIs' locations.

To conclude, these maps summarizing the expert perspective supported the integrativity of horizontal alignment through the complexity defined by the breadth and depth of concepts related to it as well as through the multi-layered relationships among them. However, as previously mentioned, these concept maps in themselves are probably be useful only as guides for other instructors to build their own.

Focusing on an integrative concept such as the horizontal alignment, instructors can build similar concept maps to integrate both own design expertise and the contextual specificity of the course in which the highway design project is included. Once this step is concluded, the next stage involved building instructional scaffolds that address the complexity of the integrative concepts analyzed with concept mapping. 




Figure 3. Decisions associated with establishing alternative PIs locations

\section{Instructional Changes to Reflect the Integrativity of Horizontal Alignment}

The highway design project was revised from the activities covering material from the textbooks to a more elaborate explanation of design principles covering location of point of intersection, design constraints for horizontal and vertical alignment, as reflected by the concept maps generated to establish the integrativity of horizontal alignment.

Considering the complexity that resulted from the analysis of integrativity of horizontal alignment, the project activities associated with this step in the project were modified. 
The initial team-based task related to the design of the horizontal alignment was changed in a series of two individual assignments followed by a team-based task. That is, the initial individual assignments were built so that they will produce learning outcomes simpler than the final outcome expected for the design of the horizontal alignment as a team. However, the learning outcomes resulted from these first two individual tasks were designed so that when combined in the first team-based task of the project will allow students to easily transfer the knowledge and skills from the individual tasks, and produce based on a team consensus the final expected outcome, the design of the horizontal alignment.

More specifically, considering the complexity of various elements in the design of horizontal alignment, in the new proposed instructional structure, the location of PIs was first carried out individually. Next, students got together in teams and starting from their individual designs of PIs locations they negotiated as a team a final pool of PIs locations that would serve as the base for the next steps in the design of the horizontal alignment for their team project.

From an instructional perspective, the individual tasks associated with the location of PIs were developed as learning scaffolds build around a simplified version of the target design task to be carried out as a team. That is, the segment of highway to be re-designed by each team of students was divided in a number of sub-segments for which students were asked specifically to identify two alternative locations of the points of intersection and to select the best of the two based on a set of given design assumptions provided by the instructor. A series of detailed instructional materials were then developed using the information synthesized in the concept maps developed by the expert for this part of the design activity. For example, Figure 4 represents a simplified version of the map presented in Figure 3. It was then included as one of the slides used by the instructor to introduce the individual task associated with PIs' locations.

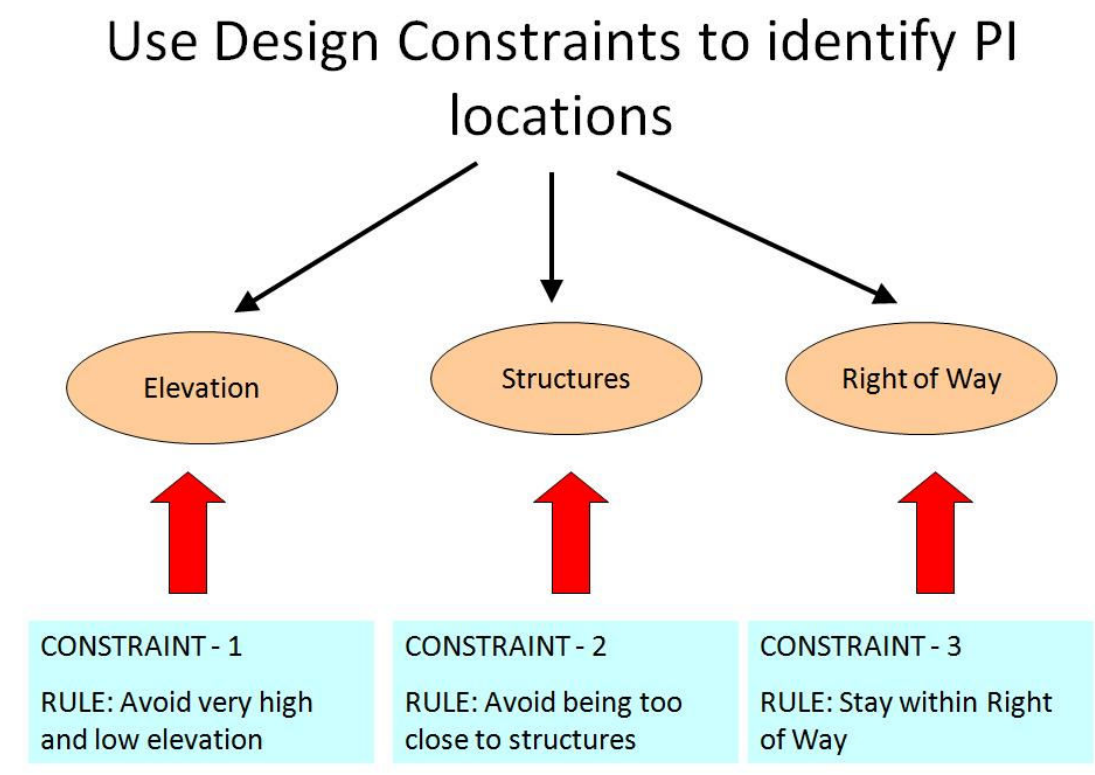

Figure 4. Sample slide used to scaffold the first individual design task 
Other concept maps were introduced in the lectures that preceded and prepared the design of horizontal alignment process. For example, Figure 5 representing the horizontal alignment design process mapped in Figure 2 as a more complex network was introduced as a slide in the lecture to make students aware of both the overall structure of the design project and on its' specific role in the learning process.

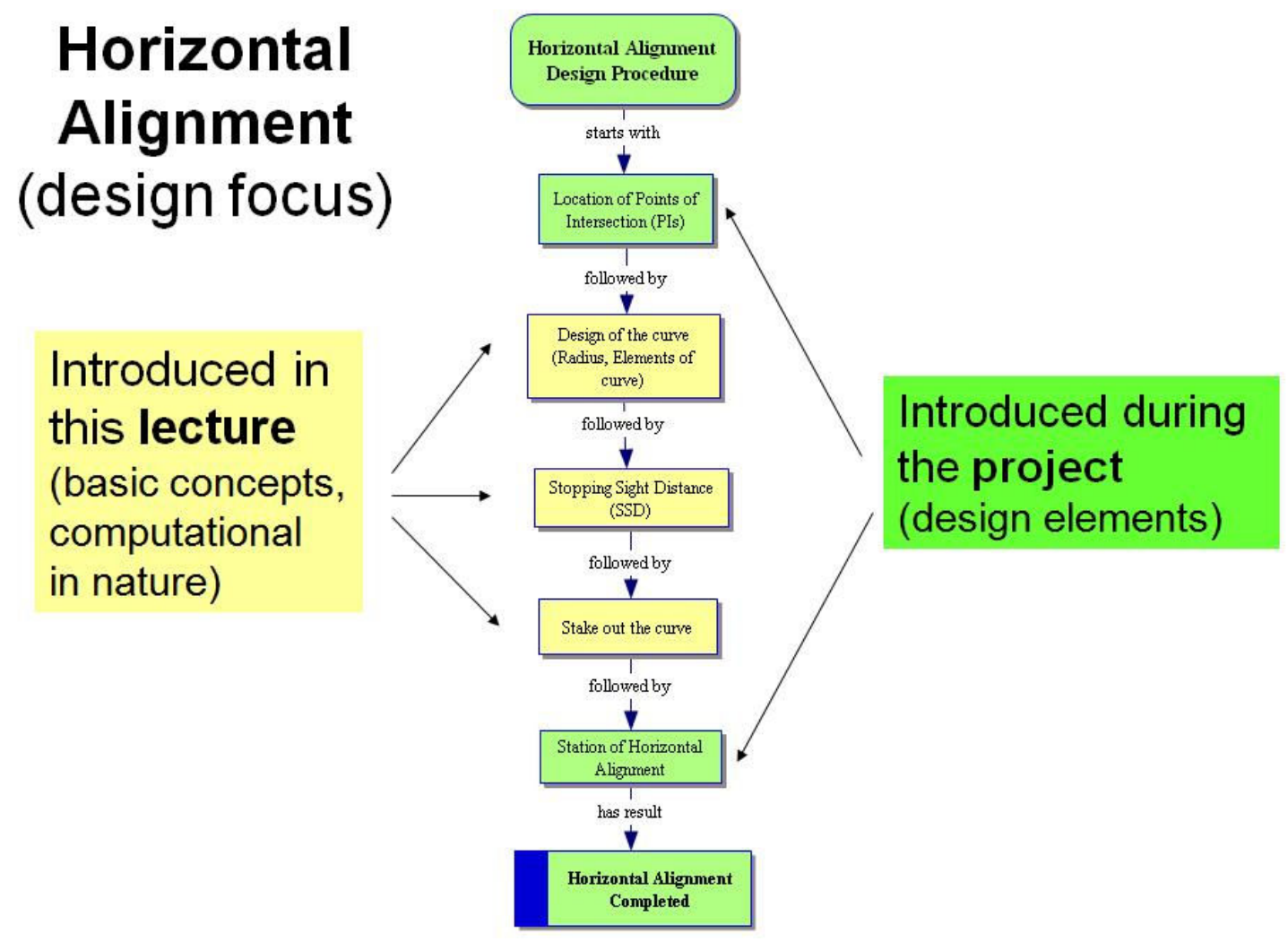

Figure 5. Sample slide used in the lecture to introduce the place of design tasks

It has to be mentioned again that the concept maps developed to analyze and explicit the integrativity of the horizontal alignment were not used directly in the instructional process. They rather served as support to, on one hand, help the instructor organize the information to be presented to the students and, on the other hand, to develop instructional materials that supplemented the information presented in textbooks.

Additionally as in the past, the project was assigned as a whole at the start of the semester, only the complete project report was due on an assigned date. In the new structure of instructional tasks, the project was divided into specific tasks with weekly due dates. These changes made the students both as individuals and as teams more responsible for completing the tasks on time. 


\section{Exploratory Evaluation of Transformativity of Horizontal Alignment}

This first implementation of the new instructional structure for the design of horizontal alignment required significant amount of resources needed to focus on the management, both of the new tasks and the overall project throughout the semester.

Therefore, as transformativity involves the measurement of a shift in students' understanding at both conceptual and ontological levels, the required research resources to address these two characteristics of transformativity were not available. However, several changes were made in the structure of students' assessment strategies to allow collecting their perceptions and attitudes toward some of the implemented changes. These changes involved the administration of a survey to collect prior knowledge, followed by reflective assessments that used open-ended questions after each of the three steps associated with horizontal alignment (two individual and one team task) and two open-ended questions regarding the highway design process that were administered with the exit survey at the end of the course.

\section{Students' Performance on Prior Knowledge Test}

Of the twenty-seven students enrolled in this class, mainly juniors and some seniors, twenty-four participated in the prior knowledge survey administered at the beginning of the first lecture of the course. The three major groups of knowledge tested were basic mathematics, basic physics and basic surveying knowledge. All items were selected by the instructor and were administered as multiple-choice items. The overall mean score for the class was $64 \%$, ranging from a minimum of $35 \%$ to a maximum of $94 \%$. Of the three prior knowledge areas tested, basic physics had the smaller mean score (50\%) while the surveying had the highest mean score $(68 \%)$.

These overall results were formally presented by the instructor in the classroom to rise students' awareness about the need to review own basic prior knowledge needed for a successful completion of this course. Also a detailed answer sheet was provided to the students and was mentioned as a resource when specific prior knowledge covered in the entry survey were used in the materials introduced in the classroom.

\section{Students' Perspectives}

The reflective assessment answers were analyzed from a qualitative perspective looking for basic theme ${ }^{25}$ associated with target characteristic, transformativity of horizontal alignment in this case. At this exploratory point of research, we searched for evidence that showed that students started to include some of the new entities associated with horizontal alignment into their own perception of the highway design process. That is, students' answers to a set of reflective questions administered after each major step in the instructional process associated with the design of the horizontal alignment as well as at the end of the course were analyzed from a qualitative perspective. 
First, we analyzed students' answers to the reflective assessment administered after the second individual assignment focusing on the location of the point of intersection in the design of the horizontal alignment. When, asked what in the first individual design exercise (selection of two alternative locations of the points of intersections) helped them to be more effective in the second individual design exercise (selection of the optimal location), 18 of the 27 students were able to explicitly identify the basic relationships between the instructional role of each exercise as well as their increasing complexity. Following are some examples that support this trend.

\section{Student 8}

I became more comfortable with determining the elements of HCC [horizontal circular curves] by working with them in Design Exercise 1.

\section{Student 9}

The two alternative intersection angles from Design Exercise 1 helped a great deal as they were used to design the curve in Design Exercise 2.

\section{Student 14}

After design exercise 1, I understood what the different elements of an HCC were and I knew the different formulas that were necessary to use from class.

\section{Student 18}

Ex 1 was very helpful with Ex 2. Ex 1 was a good base. It covered the basics of horizontal curves which gave a better understanding of ex 2 when more variables were added to the problem.

\section{Student 22}

Finding the radius and learning all the different elements of a horizontal curve from exercise one helped significantly in the calculations of the different parts in exercise two. It was also helpful that the equations were all known and easy to compute.

\section{Student 25}

In design exercise 1 , we were asked to make most of the calculations that make up the horizontal curve, so when we were asked to do them again in design exercise 2, they were much easier. Also, there was a better understanding of the vocabulary needed to complete the exercise because of knowledge gained in the previous exercise.

\section{Student 26}

Knowing the parts of the horizontal circular curve helped in the determination of the qualitative analysis of the curve. Points like the PI, PC, and PT were used to determine the other characteristics of the curve.

However, of the nine students that did not provided an explicit link between the instructional roles of the two individual steps in the design of horizontal alignment, one answered "..... i dono" and two suggested a low or no usefulness of the first individual exercise:

\section{Student 17}

It didn't do much except give me my delta angle I needed for exercise 2. 


\section{Student 10}

I believe that we could have done Exercise 2 without doing exercise 1 first.

These findings suggest that the instructional changes in this part of the course reached most of the students but as usual, more can be done to address students' individual needs both at the low and high end of knowledge scale.

A second set of reflective questions were also administered after the first team task. As a reminder, this first team task asked students to transfer the knowledge and skills they built during the first two individual tasks to a similar but more complex task and negotiate a common solution. At this point students were asked if they feel that the goal of having the individual exercises help them design the PIs as a team was met. For this stage, students' answers showed a wider spread of opinions as compared to the answers provided for the previous step.

More than half of the answers (14 out of 27 students) were positive, with several of them showing a clear understanding of the role of the proposed structure for the instructional tasks associated with horizontal alignment. Below are several examples that support this trend in students' answers.

\section{Student 7}

Yes this goal was met, the design of the horizontal alignment was fairly easy with the help of design exercise 1 and 2 .

\section{Student 8}

Yes, I feel this goal was met because each part of Design Exercises 1 and 2 helped me learn and develop the skills needed in designing the horizontal alignment.

\section{Student 12}

Yes, we completed design exercise 1 and 2 with the future labs in mind so that we would have to make minimal changes.

\section{Student 16}

Yes because we all knew what to do we just needed to all do it together and agree the best way to do it.

\section{Student 18}

The first two exercises did a good job in preparing me. I was better prepared when doing the actual curve for our project than if $i$ wouldn't have done them.

\section{Student 19}

Yes, it helped us become more aware of what we were going to be doing so we had a good idea of what was going on before we started.

\section{Student 20}

I think it [the goal to prepare us] was met pretty well, it helped us better understand how and why we did what we did for exercise 3. 


\section{Student 22}

Yes, lab exercise 1 and 2 helped significantly because our group spent a large amount of time individually on each section, and when we combined all the layouts in exercise 3 it was a very smooth process. We had already come up with the best design layout of the highway and compared to make sure they would align properly.

\section{Student 25}

Yes. After the first two exercises, the team horizontal alignment was fairly simplistic.

The remaining 13 of the students were split in two relatively equal groups. A first group of 6 students reported perceiving some value for the individual tasks but complaining about the clarity of the guidance for the first team step. Some sample answers from this category are presented below.

\section{Student 2}

Yes, other than a lack of instruction on Exercise 3. It was never explained that the first and last tangents had to align with a straight portion of the existing alignment. We were told we just needed $200 \mathrm{ft}$ straight before starting and ending the curves.

\section{Student 4}

I don't feel that we were ready, we had several things that we were unsure of. We got them figured out but those problems caused us to have to do exercise 3 more than once.

\section{Student 14}

I personally think that these two exercises helped to prepare but were not as effective as they could have been. The one thing that was not discussed in these was how to connect different curves on the highway, which seemed to be the main problem for a lot of people.

\section{Student 26}

The exercises 1 and 2 would have been more productive if they did not have to be changed. This did not help us work in a group because we had to individually redo the curves that we had made before, and then alter them again when we tried to make them align with each other.

A second group of 7 students clearly indicated that the first two individual tasks were not useful for them in the first team task. Some sample answers from this category are presented below.

\section{Student 5}

No, because exercise 2 only asked us to check the curves using the SSD design and this was not appropriate. Also, the superelevation given in exercise two was not the superelevation desired for our design as a group but this was not conveyed to the class.

\section{Student 6}

Not really. The idea was to minimize any conflicts with designing new alternatives. So any of the original ideas were not used.

\section{Student 13}

No because the objectives were not clear in exercise one and two as to what needed to be done on ex 3 [first team task]. 


\section{Student 21}

NO. The way we did the first 2 labs was we could choose to place our PI's wherever we wanted. There were not near as many constraints and then we are told after exercise 3 that the locations chosen do not work.

These two final groups of answers suggest two possible issues that need to be addressed in the future iterations of these instructional tasks. First, from the students' inputs it can be inferred that some students' expected that the entire outcome of their individual tasks will be readily transferred to the team task. This suggests the need to revise the instructional materials associated with the first two individual tasks so that the student will build the right expectations regarding the role and value of the outcomes in these tasks.

Second, some of the negative input suggests that some of the student teams were not able to create a strong enough bond to move on as expected when the first team task was assigned. This finding suggests that in the future the instructor will have to encourage students to start the team building process during the individual tasks so that when the first team task is assigned, the link among team members will be established and the transfer of skills from the individual to the team task will be better facilitated.

Students' answers after each of these major instructional tasks are a good indicator of the shortterm impact of these changes on individual perceptions related to the design of horizontal alignment. Even if these short-term changes are important seeds for a significant transformation of students' perceptions about the role of horizontal alignment in their learning of highway design skills, we tried to move one step further and test the impact of these initial changes on long term. As a first step in this direction in the course exit survey students were asked to answer two short open-ended questions associated with the highway design activities they experienced in the course. Twenty four of the twenty sevens students enrolled in this course participated in this exit survey. However, for reporting consistency the student number shown when sample answers are presented will be the same as reported when all 27 students participated in the study.

The first question asked students to name the major steps in the highway design process to test if horizontal alignment became part of their professional ontology. We found that a large majority of students (19 of the 24) explicitly included this concept in their answers in various forms: horizontal alignment, horizontal layout, horizontal curves, horizontal circular curve alignment, or horizontal design. Of the remaining five students, two used a more generic, global perspective such as "Planning, design, redesign, construction, then maintaining." (Student 18), and three indicated a structure more closely related to the topics introduced toward the end of the course than to the design project, such as "Trip generation, trip distribution, mode choice, and trip assignment to network" (Student 4).

The second question asked what are the two most critical steps in the highway design process and why. Fifteen students out of the 24 participants in this phase of the study included in their answer the concept of horizontal alignment. More important from a transformativity perspective is that several of these answers showed a good understanding of the role of this concept in the overall highway design process. 


\section{Student 1}

Designing the horizontal and vertical curves. This determines the layout of the roadway and ensures that the highway does not face obstructions. Other design steps are all dependent on the setting of the horizontal and vertical curves.

\section{Student 6}

Horizontal and Vertical alignment. They directly influence any other calculations, decisions, and recommendations.

\section{Student 8}

The horizontal curves because it is important to choose a route that does not run into structures/trees/etc. and is not too steep/sharp.

\section{Student 12}

The two most critical steps are horizontal and vertical alignment because this dictates your cost because demolition is controlled by these two things as well as your earthwork costs. Also, intersection design is dependent on the horizontal and vertical alignment as well.

\section{Student 22}

Horizontal alignment and vertical alignment are the most important because they will determine the other parts of the design process. If the alignments are done correctly the other processes should be very economical.

\section{Student 25}

Horizontal and Vertical Alignment. All other aspects of design: stopping sight distance, cut and fill, superelevation, etc. relate to these two things.

The remaining nine students provided answers that, to some degree mapped the groups of topics that were found for the previous question administered in the exit survey. That is, three students used the more global perspective that included design, planning, and cost as the main critical steps in highway design, while the rest of them indicated topics covered toward the end of the course such as trip generation, trip distribution and safety.

Considering the limitations of this study due to the novelty of its structure for both the instructor and the students, we consider these examples as providing some initial support to consider horizontal alignment to be a transformative concept. Therefore, when appropriately used, the design of horizontal alignment can serve as a strong instructional scaffold to enhance students' learning of highway design process. However, as with any instructional intervention, this approach is not a panacea that will help solve all instructional needs of students engaged in building design-related knowledge and skills. The feedback collected in this exploratory study showed that for some students the process could still be difficult. However, the same feedback also can serve to identify possible changes in the instructional process that will expand the pool of students that will be successful in mastering desired design skills. One further step toward this goal is to have also the instructor engaged in a reflective analysis of the strengths and weaknesses of this first implementation of threshold concepts' characteristics in refining the instructional process associated with the highway design process. 


\section{Instructor's Perspective}

The mapping of different concepts and the flow of information leading to design provided the right tools and helped in explaining the design principles and concepts to the class. Previous experience of instructor with the course reflected frustration of students with the design project especially with the horizontal and vertical design portions of the project. The horizontal and vertical design aspects were considered vague and challenging. This was made worse by textbooks that do not cover design aspects in detail such as location of PIs. The systematic sequential approach as indicated in Figure 2a, the design constraints presented in Figure 3, and dividing the activities into individual assignments and then combining the activities to reach a consensus decision provided a much needed awareness and confidence in the students to perform highway design. This also had a positive impact on the students.

The student hesitation in choosing the PI locations for horizontal alignment and similarly the vertical points of intersection (VPI) for vertical alignment was overcome as a result of activities divided into individual responsibilities and then joint decisions. With the presentation of design constraints, similar to Figure 3, the students kept the bigger constraints in mind, while carrying out the design. Similar constraints were also provided for other design aspects. The graphical presentation both improved the quality of instruction and addressed different learning styles.

Additionally, based on the concept maps, grading rubrics for project presentation, final report and various intermediate project assignments were developed. These concepts maps provided the essential items to evaluate student assignments in the larger context.

Thus, the threshold concepts served as a valuable instructional design tool to provide useful instructional scaffolds for the instructor engaged in highway design courses. The material prepared will serve as a starting point in developing more complex research design to allow a more in depth evaluation of transformativity of horizontal alignment.

\section{Conclusions and Future Research}

The major limitation of this study was its exploratory nature grafted along an evolving instructional process that was new for both the instructor and his students. The high load imposed by the development and subsequent management of this instructional process placed limitations on the development of more sophisticated research tools, especially those related to the measurement of transformativity of the proposed target concept. Considering the above mentioned limitations this study was able to:

a) Identify horizontal alignment as a candidate-concept with a significant integrativity to provide support for improving the instructional process associated with students' learning of highway design;

b) Implement the proposed instructional changes to scaffold students' learning of highway design process; and

c) Find some trends in students' reflective assessment items that support the potential of horizontal alignment to act as a threshold concept for the learning of knowledge and skills associated with highway design. 
We proposed to use concept mapping as a tool to, on one hand establish the integrativity of horizontal alignment and, on the other hand to build instructional scaffolds to support students' learning of highway design skills. These changes resulted in trends of students' better understanding of the highway design process and of the role and importance of horizontal alignment in this process. These trends resulted from the analysis of students' reflective assessment questions developed to monitor the impact of the new instructional tasks. We plan to extend this exploratory study in a more structured analysis of students' performance outcomes for various steps complemented with a series of exit interviews that will target specific aspects of students' understanding of the highway design process.

\section{References}

1. Jonassen, D. H. (2004). Learning to Solve Problems. An Instructional Design Guide. San Francisco, CA, Pfeiffer, A Wiley Imprint.

2. Sun, C., Recker, W., Ritchie, S., Gallagher, B., Shen, E., and J. Thai (1997). Oak-Tree: One-Of-a-Kind Traffic Research and Education Experiment. Transportation Research Record: Journal of Transportation Research Board, 1603, Transportation Research Board of the National Academies, Washington, D.C.

3. Luna, R., R. Hall, M. Hilgers, G. H. Bham, R. Elgin, C. Morris, and G. Morrison (2008). Introduction of GIS into Civil Engineering Curricula, AC 2008-2791, ASEE Annual Conference, Pittsburgh, PA .

4. Meyer, J., and Land, R. (2003) Threshold Concepts and Troublesome Knowledge: Linkages to Ways of Thinking and Practicing within the Disciplines. Occasional Report 4. Edinburgh, UK: University of Edinburgh, Coventry and Durham.

5. Meyer, J., and Land, R. (2005). Threshold concept and troublesome knowledge (2): Epistemological considerations and a conceptual framework for teaching and learning. Higher Education, 49, 373-388.

6. Cousin, G. (2006). An introduction to threshold concepts. Planet, 17, 4-5.

7. Chi, M.T.H. (1992). Conceptual Change Within and Across Ontologies. Examples from Learning and Discovery in Science. Minnesota Studies in the Philosophy of Science, 15, 129-186.

8. Reimann, N., and I. Jackson (2006). Threshold Concepts in Economics. In J. Meyer and R. Land (Eds.), Overcoming Barriers to Student Understanding. New York, NY: Routledge, 115-133.

9. Taylor, C. (2006). Threshold Concepts in Biology. In J. Meyer and R. Land (Eds.), Overcoming Barriers to Student Understanding. New York: Routledge, 87-99.

10. Taylor, C., and C. Cope (2007). Are there educationally critical aspects in the concept of evolution? Proceeding of the Assessment in Science Teaching and Learning Symposium, University of Sydney, 101-106, Available online at: http://science.uniserve.edu.au/pubs/procs/2007/2021.

11. Khalife, J. T. (2006). Threshold for the Introduction of Programming: Providing Learners with a Simple Computer Model. Proceedings of the 18th Workshop of the Psychology of Programming Interest Group, University of Sussex, 244-254.

12. Bulmer, M., O'Brien, M., and S. Price (2007). Troublesome concepts in statistics: a student perspective on what they are and how to learn them. Proceeding of the Assessment in Science Teaching and Learning Symposium, University of Sydney, 9-15, Available online at: http://science.uniserve.edu.au/pubs/procs/2007/2009.pdf.

13. Eadson, D. (2007). The role of proof in mathematics teaching and The Plateau Principle. Proceeding of the Assessment in Science Teaching and Learning Symposium, University of Sydney, 28-33, Available online at: http://science.uniserve.edu.au/pubs/procs/2007/2009.pdf.

14. Bernhard, J., and A. K. Carsternsen (2007). Modeling and learning a complex concept - an exploration in light of some examples from electric circuit theory. Paper presented at the ESERA, Malmo, 21-25.

15. Bartlett, F. C. (1932). Remembering: A Study in Experimental and Social Psychology: Cambridge University Press.

16. Norman, D. A., Gentner, D. R., and A.L. Stevens (1976). Comments on Learning Schemata and Memory Representation. In D. Klahr (Ed.), Cognition and Instruction, Hillsdale, NJ: Lawrence Erlbaum Associates, 177196. 
17. Preece, P. F. (1976). Mapping Cognitive Structure: A Comparison of Methods. In: Journal of Educational Psychology, 68(1), 1-8.

18. Rumelhart, D. E., and A. Ortony (1977). The Representation of Knowledge in Memory. In R. C. Anderson, R. J. Spiro and W. E. Montague (Eds.), Schooling and the acquisition of knowledge. Hillsdale, NJ: Lawrence Erlbaum Associates, 99-135.

19. Thagard, P. (1992). Conceptual Revolutions. Princeton, NJ: Princeton University Press.

20. Jonassen, D. H., Beissner, K., and M. Yacci (1993). Structural Knowledge: Techniques for Representing, Conveying, and Acquiring Structural Knowledge. Hillsdale, NJ: Lawrence Erlbaum Associated, Publishers.

21. Grotzer, T.A. (2002). Expanding our Vision for Educational Technology: Procedural, Conceptual, and Structural Knowledge. Educational Technology, 42(2), 52-59.

22. J. Alonso-Tapia, J. (2002). Knowledge Assessment and Conceptual Understanding. In M. Limon and L. Mason (Eds.), Reconsidering Conceptual Change. Issues in Theory and Practice. Netherlands: Kluwer Academic Publishers, 389-413.

23. Garber, N.J. and Hoel, L.A. (2009). Traffic and Highway Engineering. $4^{\text {th }}$ Edition. Toronto, Canada: Cengage Learning.

24. Easa, S. M., and A. Mehmood (2007). Establishing Highway Horizontal Alignment to Maximize Design Consistency, In: Journal Title Canadian Journal of Civil Engineering, 34(9), National Research Council of Canada, 1159-1168.

25. Bogdan, R.C. and Biklen, S.K. (1998). Qualitative Research for Education. Third Edition. Boston: MA, Allyn and Bacon. 